\title{
MU'JAM LUGHAWIY DAN PEROBLEMATIKA PENGGUNAANNYA DALAM PEMBELAJARAN BAHASA ARAB PADA MAHASISWA DI KOTA BIMA
}

\author{
Ahmad Syagif Hannany Mustaufiy \\ STIT Sunan Giri Bima \\ Email : 4gyptik@gmail.com
}

\begin{tabular}{|c|c|c|c|}
\hline Submit & Received & Edited & Published \\
\hline 31 Des. 2021 & 01 Jan. 2021 & 03 Jan. 2021 & 05 Jan. 2021 \\
\hline
\end{tabular}

\begin{abstract}
Mu'jam Lughawiy has crucial or even inseparable uses. Mu'jam Lughawiy has become a favorite tool for language learners. especially when faced with activities to find the meaning of a word. grammar. or the context of its use in the desired language. History also records that Mu'jam Lughawiy went through several stages of development. both in terms of its composition and the systematics of its writing along with its pluses and minuses. So therefore. This paper seeks to identify the problems faced by students in Bima City when using Mu'jam Lughawiy in learning Arabic. This paper can contribute positively to educators. learners. as well as foreign language practitioners, especially Arabic as initial information related to the problems faced by students when using Mu'jam Lughawiy so that they can be used as references in finding alternative solutions to various obstacles encountered when interacting with Mu'jam Lughawiy. This study applies a qualitative approach through the case study method and uses semi-structural interviews as a data collection technique and thematic analysis methods as a data analysis technique that has been obtained. In determining students as participants. The author applies a purposive sampling technique based on the student population at Islamic Higher Education in the City of Bima. This paper concludes that students' problems when using Mu'jam Lughawiy in Arabic learning are dominated by linguistic factors due to weak grammatical abilities as a result of weak learning motivation and problems in the Arabic learning process at the previous level. Students are more interested in interacting with Mu'jam Lughawiy in the form of software that uses an articulation system because of the financial efficiency factor.
\end{abstract}

\section{ABSTRAK}

Mu'jam Lughawiy memiliki kegunaan yang krusial atau bahkan tidak bisa dipisahkan. Mu'jam Lughawiy telah menjadi sarana favorit para pembelajar bahasa. terutama ketika dihadapkan pada aktivitas mencari makna suatu kata. tata bahasa. atau konteks pemakaiannya dalam bahasa yang diinginkan. Sejarah juga mencatat bahwa Mu'jam Lughawiy mengalami beberapa tahapan perkembangan. baik terkait segi susunannya maupun sistematika penulisannya berikut plus dan minusnya. Maka dari itu. melalui tulisan ini berupaya untuk mengidentifikasi seputar probematika yang dihadapi mahasiswa di Kota Bima saat menggunakan Mu'jam Lughawiy dalam pembelajaran Bahasa Arab. Penelitian ini mengaplikasikan pendekatan kualitatif melalui metode studi kasus dan menggunakan wawancara semi struktural sebagai teknik pengumpulan data serta metode analisis tematik sebagai teknik analisis data yang telah diperloleh. Dalam menentukan mahasiswa sebagai partisipan. penulis mengaplikasikan teknik purposive sampling berdasarkan populasi mahasiswa pada Perguruan Tinggi Islam di wilayah Kota Bima. Hasilnya ialah problematika mahasiswa saat penggunaan $\mathrm{Mu}$ 'jam Lughawiy dalam pembelajaran Bahasa Arab didominasi oleh faktor linguistik karena lemahnya kemampuan gramatikal sebagai akibat dari lemahnya motivasi beajar, serta problematika dalam proses pembelajaran Bahasa Arab di jenjang sebelumnya. Mahasiswa lebih tertarik berinteraksi dengan Mu'jam Lughawiy dalam bentuk perangkat lunak yang menggunakan sistem artikulasi karena faktor efisiensi finansial. penggunaan yang mudah dan praktis.

Kata Kunci : Problematika. Mu’jam Lughawiy. Bahasa Arab

\begin{tabular}{|c|c|c|c|c|c|}
\hline $\begin{array}{c}\text { Volume } \\
12\end{array}$ & Nomor & Edisi & P-ISSN & E-ISSN & Halaman \\
& 2 & Deseber 2021 & 20857365 & $2722-3027$ & $34-52$ \\
\hline
\end{tabular}




\section{PENDAHULUAN}

Diantara fitrah manusia yang harus dieksplorasi dan dikembangkan dalam diri pembelajar adalah sisi Bahasa. Hal ini disebabkan karena sejak anak dilahirkan telah dibekali dengan potensi berbahasa dalam dirinya yang diawali dengan tahapan meraba. menghafal kata. menghafal nama. serta mengidentifikasi objek secara bertahap hingga menyentuh hal-hal yang kompleks. Bahasa menjadi aspek urgen dalam kehidupan individu karena melalui bahasa. seorang individu dapat berkomunikasi satu sama lain. Menurut beberapa pakar bahasa merupakan sistem lambang bunyi yang memiliki sifat arbitrer. yang dimanfaatkan oleh individu-individu dalam suatu komunitas dalam rangka aktifitas kerja sama. interaksi. dan identifikasi diri. ${ }^{1}$ Bahasa telah dipelajari manusia sejak kecil sebagai alat berkomunikasi dengan sekitarnya. Jika seorang anak telah memperoleh bahasa pertamanya. maka selanjutnya ia akan memasuki tahapan pemerolehan bahasa kedua. melalui apa yang diistilahkan dengan pembelajaran bahasa. Bahasa kedua bagi seseorang dapat berupa bahasa nasional. bahasa formal kenegaraan. bahasa daerah. hingga bahasa asing. ${ }^{2}$

Bahasa Arab yang merupakan salah satu bahasa asing bagi masyarakat Indonesia yang tidak hanya memiliki kedudukan sebagai bahasa berkomunikasi. namun juga sebagai bahasa dua sumber hukum utama dalam Islam yakni Al-Quran dan hadits. serta Bahasa yang digunakan dalam kitab-kitab keagamaan lainnya. Secara normatif Bahasa arab juga diyakini sebagai Bahasa penghuni surga dan salah satu Bahasa resmi di PBB. Populasi muslim di seluruh penjuru dunia yang berjumlah mencapai 1 milyar. juga menempatkan bahasa Arab sebagai bahasa dalam kegiatan kajian. pembelajaran dan perkuliahan di berbagai institusi pendidikan. ${ }^{3}$ Oleh sebab itu bahasa Arab dianggap sebagai perangkat pokok untuk mendalami tentang Islam dan seluruh ajaran di dalamnya. Fakta inilah yang menjadi pertimbangan penting sehingga bahasa Arab menjadi mata pelajaran wajib di semua jenjang Pendidikan baik yang berada di bawah Kementerian Agama maupun Kementrian Pendidikan dan Kebudayaan yang berciri khas Islam. mulai dari tingkat dasar (Madrasah Ibtidaiyah). menengah (Madrasah Tsanawiyah dan Madrasah Aliyah). maupun tingkat Pendidikan tinggi seperti pada Perguruan Tinggi Keagamaan Islam.

\footnotetext{
1 Rina Devianty. 'Bahasa Sebagai Cermin Kebudayaan'. JURNAL TARBIYAH. 24.2 (2017) $<$ https://doi.org/10.30829/TAR.V24I2.167>.

${ }^{2}$ Tisa Maharani and Endang Setiyo Astuti. 'Pemerolehan Bahasa Kedua Dan Pengajaran Bahasa Dalam Pembelajaran BIPA'. Jurnal Bahasa Lingua Scientia. $10.1 \quad$ (2018). $121-42$ $<$ https://doi.org/10.21274/LS.V10I1.938>.

3 A Mualif. 'Orisinalitas Dan Elastisitas Kosakata Dalam Bahasa Arab'. (LISANUNA): Jurnal Ilmu Bahasa Arab Dan Pembelajarannya. 9.1 (2020). 40-51 <https://doi.org/10.22373/LS.V9I1.6731>.
} 
Seseorang yang mempelajari Bahasa asing akan membutuhkan dua hal. ${ }^{4}$ yaitu (1) kemampuan reseptif. sebagaimana dalam memahami teks tertulis dan audio. dan (2) kemampuan produktif. sebagaimana halnya dalam aktifitas berbicara dan menulis. Diantara proses yang diperlukan untuk memahami bahasa asing termasuk diantaranya Bahasa Arab adalah dengan cara aktifitas terjemah. Penerjemahan merupakan istilah bagi kegiatan pemindahan makna dari bahasa sumber ke bahasa sasaran. karena makna kata merupakan bagian sentral sebuah aktivitas penerjemahan. ${ }^{5}$ Ketika mempelajari bahasa Arab. mu'jam lughawiy dapat memberikan manfaat besar. bahkan menjadi kebutuhan utama. Mu'jam lughawiy menjadi sarana yang paling diminati oleh pembelajar Bahasa disaat ingin mencari makna kata. kaidah bahasa. atau konteks penggunaan kata dalam bahasa sasaran yakni Bahasa Arab.

Dalam lintasan sejarah mu'jam lughawiy tercatat pernah mengalami beberapa tahapan transformasi. baik dalam segi penyusunannya maupun sistematika penulisannya berikut plus minusnya. Di setiap tahapan tersebut. bisa dipastikan bahwa bentuk dan model mu'jam lughawiy yang banyak beredar dan dimanfaatkan oleh pengguna maupun yang ingin mempelajari bahasa Arab sampai saat ini. tentu saja mendapat respon yang bervariasi dan mempunyai kecenderungan masing-masing untuk digunakan berdasarkan kebutuhan penggunanya serta berbagai kendala yang dihadapinya.

Berdasarkan hal tersebut. tulisan ini merupakan usaha untuk mengidentifikasi jawaban atas rumusan masalah seputar problematika penggunaan mu'jam lughawiy dalam pembelajaran Bahasa Arab. khususnya bagi mahasiswa di Kota Bima. Tulisan ini dapat berkontribusi bagi para pendidik. pembelajar khususnya mahasiswa. maupun praktisi Bahasa Arab sebagai informasi terkait problematika penggunaan mu'jam lughawiy dalam pembelajaran Bahasa Arab agar dapat menjadi referensi dalam memilih kamus yang representatif dan menemukan jalan keluar atas kendala tersebut.

\section{Definisi Mu'jam Lughawiy}

Kata Mu'jam berasal dari Bahasa Arab yang berasal dari akar kata a'jama yang secara etimologis berarti "menghilangkan kekaburan dan ketidakjelasan". Melalui pemaknaan secara morfologis sebagaimana di atas. maka penggunaan kata mu'jam yang merujuk makna kamus dianggap cukup relevan karena dari segi fungsi. kamus berguna untuk menghapus hal-hal yang masih ambigu. Secara terminologis mu'jam didefinisikan

\footnotetext{
${ }^{4}$ Miftachul Taubah and Ilzam Dhaifi. 'Reseptif Dan Produktif Dalam Bahasa Arab'. Lahjah Arabiyah: Jurnal Bahasa Arab Dan Pendidikan Bahasa Arab. $1.1 \quad$ (2020). 33-36 $<$ https://doi.org/10.35316/LAHJAH.V1I1.574>.

${ }^{5}$ Siti Shalihah. 'Terjemah Bahasa Arab Antara Teori Dan Praktik'. At-Ta'dib. 12.2 (2017). 183-202 $<$ https://doi.org/10.21111/AT-TADIB.V12I2.1144>.
} 
sebagai kitab yang menghimpun sekumpulan kosakata Bahasa tertentu dan dilengkapi beberapa penjelasan atau penafsiran maknanya. dengan materi yang diatur dengan susunan tertentu baik mengikuti urutan abjad hija'iyah maupun menyesuaikan dengan topik. ${ }^{6}$

Para pakar kebahasaan umumnya menggunakan lafadz mu'jam untuk sebutan alternatif bagi kata "kamus". ternyata dalam sejarahnya merupakan istilah yang banyak digunakan oleh muhadditsin. Hal ini sebagaimana tercantum pada kitab Shahih karangan Imam Bukhari (w.870 M.) yang menulis kata "Huruful Mu'jam" pada bab: "Tasmiyatu man summiya min ahli badrin". Demikian juga pada karya Ibn Mutsanna (w.919 M.). beliau memberi judul kitab hadisnya dengan redaksi "Mu'jam al-Shahabah" dan Abu alQasim al-Baghawi (w.929 M.) yang menyusun dua karangan fenomenal berisi daftar biografi sahabat Nabi SAW dengan judul "al-Mu'jam al-Kabir" dan "al-Mu'jam alShaghir". Selanjutnya. pada kurun keempat hijriyah. penggunaan istilah Mu'jam semakin meluas di kalangan para ulama hadis seperti . "Mu'jam al-Syuyukh" yang disusun oleh Ibn Marzuq al-Baghdady (w.962 M.) dan "Mu'jam al-Syuyukh" yang ditulis oleh Abu Bakr Ahmad ibn Ibrahim Al-Isma'ily (w.982 M.) sebanyak tiga jilid. ${ }^{7}$

Kata $M u^{\prime} j a m$ sering diidentikkan dengan kata Arab qamus yang memiliki makna bahasa samudera. laut. atau tengah lautan. ${ }^{8}$ Berdasarkan pemaknaan tersebut . dapat dipahami bahwa sebagian besar ulama yang mengarang kamus Arab pada masa dahulu tidak jarang mencantumkan judul pada kamus tulisannya masing-masing dengan nama qamus dengan harapan agar apa yang mereka tulis menjadi buku atau kamus yang kompleks. lengkap dan memuat segala hal sebagaimana samudera yang luas. dalam yang di dalamnya hidup segala macam ikan dan makhluk hidup maupun yang mati. Hingga lahirlah Fairuz Az-zabady (w.1414) yang secara langsung memberi judul kamusnya yang cukup tebal dan lengkap dengan redaksi "al Qamuus al-Muhiith" (Kamus Samudera). Karena begitu monumental dan bersejarahnya kamus karya Fairuzzabady ini sehingga beliau didaulat sebagai penggagas pertama kali yang mempopulerkan istilah Qamuus yang merujuk makna sebuah kamus bahasa. ${ }^{9}$

\footnotetext{
${ }^{6}$ Suhaimi Suhaimi. 'Mu'Jam `Arabia Dan Urgensinya Dalam Pembelajaran Bahasa Arab Di Perguruan Tinggi Agama Islam'. JURNAL ILMIAH DIDAKTIKA: Media Ilmiah Pendidikan Dan Pengajaran. 12.1 (2011). 134-48<https://doi.org/10.22373/JID.V12I1.443>.

${ }^{7}$ Ibid. 7

8 Ar-Razy. Muhammad bin Abu Bakar bin Abdul Qadir. Mukhtar al-Shihaah. (Beirut: Maktabah Lubnan. 1995). 230.

9 Taufiqurrochman. Pengembangan Kamus Tarbiyah Arab-Indonesia. Indonesia-Arab (UIN Maliki Malang. 2015). 7
} 
Adapun terminlogi kamus menurut Ahmad Abdul Ghafur Atthar adalah: "sebuah buku yang memuat kosakata bahasa dalam jumlah besar beserta penjelasan. interpretasi atau penafsiran maknanya yang disusun dengan aturan atau sistematika tertentu. baik berdasarkan urutan huruf hijaiyyah (lafal) atau tema tertentu (makna)"10 Terdapat sejumlah kata dalam khazanah linguistik arab yang digunakan untuk merujuk pada makna kamus. yaitu mu'jam. qamus. fihris. mausu'ah dan musrid. Berbagai istilah tersebut mengerucut kepada satu pemahaman. bahwa kamus. ensiklopedia. indeks. glosarium adalah himpunan mufradaat yang diberi penjelasan terkait makna atau artinya dan keterangan lainnya berfungsi untuk memberikan informasi yang berkaitan dengan kosakata yang ada dalam daftar. Seluruh kosakata berikut artinya diurutkan dalam rangkaian sistematis bedasarkan pola khusus yang diinginkan oleh penyusun kamus untuk memberikan kemudahan bagi yang memanfaatkan kamus ketika mencari makna dan informasi secara tepat tentang kata yang diinginkan agar dapat memahaminya dengan benar. $^{11}$

Kamus juga dapat dikatakan sebagai produk tradisi tulis-menulis. yang karena faktor ekonomi. politik. maupun religius menjadi alat hasil karya anak adam untuk mengerti akan bahasa asing. agar terjadi komunikasi yang lebih efektif antar individu yang berbeda bahasanya. Bahkan mulai saat pertama kali alat cetak ditemukan. kamus berfungsi penting dalam menyimpan perbendaharaan bahasa sebuah peradaban yang mustahil dapat direkam dalam otak manusia. ${ }^{12}$ Semenjak para leksikolog mempopulerkan kata Qamus. istilah ini dijadikan konsensus oleh khalayak umum yang dimaknai sebagai istilah untuk buku yang memuat kumpulan makna kata-kata (kamus). Bahkan julukan Qamus juga disematkan pada seseorang yang menyusun kamus. ${ }^{13}$ Pada masa kini. penamaan kamus bahasa pada umumnya lebih sering menggunakan istilah Qamuus daripada Mu'jam. khususnya pada kamus-kamus bilingual (dwibahasa). Meskipun demikian dalam tulisan ini penulis akan lebih fokus menggunakan istilah Mu'jam karena sangat identik dengan istilah Qamuus. Karena itulah mu'jam lughawiy dalam tulisan ini penulis batasi definisinya pada kamus kebahasaan yaitu Kamus Bahasa Arab bilingual.

\section{Fungsi dan Manfaat Penyusunan Mu'jam Lughawi}

Mu'jam lughawiy memiliki peran sentral dan urgen untuk memberikan penjelsan terkait makna bahasa bahkan dari waktu ke waktu. artikulasi (pengucapan) kata. ketepatan huruf hija'iyah. menemukan kata dasar. pejelasan aspek-aspek morfologis dan

\footnotetext{
${ }^{10}$ Ahmad Abdul Ghafur Atthar. Muqaddimah Al-Shihah. (Beirut. Dar Al-Ilm Lil Malayin. 1979). 38.

${ }^{11}$ Taufiqurrahman.. Leksikologi Bahasa Arab. (Malang: UIN Malang Press. 2008). 133-134

12 Ahmad Izzan. Metodologi Pembelajaran Bahasa Arab. (Bandung: Humaniora. 2009). 190.

${ }^{13}$ Wajdy Rizqi Ghaly dan Husain Nassar. (1971). Al-Mu’jamaat Al-Arabiyyah Biblughrafiyah Syamilah Masyruhah. (Kairo: al-Haiee ah al-Mishriyah al-A“mmah. 1971). 217-219.
} 
sintaksis (ilm as-sharf-ilm an-nahw) seperti dari aspek bentuk dan pola fi'il (kata kerja) nya. tadzkir maupun ta'nitsnya. mufrad tatsniyah serta jama'nya. Disamping itu. mu'jam lughawiy juga memuat informasi pemakaian kata sesuai konteksnya. baik dari aspek historis. kepopulerannya. topiknya. frekuensi pemakaiannya maupun informasi non kebahasaan lainnya. ${ }^{14}$ Hal-hal tersebut sangat dibutuhkan oleh seseorang yang ingin belajar bahasa Arab. khususnya bagi penutur selain Arab.

Selain itu dalam pandangan Ahmad Mukhtar Umar. mu'jam lughawiy memiliki fungsi menerangkan teknik pengucapan kata dengan memakai syakal. baik secara langsung maupun dianalogikan pada kata lainnya. Selain itu melalui mu'jam lughawiy juga dapat diketahui informasi teknik menulis suatu kata. terutama jika menjumpai huruf yang tidak ditemukan kesamaan abjadnya. ${ }^{15}$ Karena itulah mu'jam lughawiy memiliki eksistensi penting untuk menjelaskan suatu Bahasa asing baik secara lisan maupun tertulis.

Mu'jam lughawiy merupakan "jantung" ketika mengkaji bahasa. termasuk bahasa Arab. sebab hampir tidak mungkin untuk mempelajari bahasa asing bila tidak menggunakan Mu'jam lughawiy. Mu'jam lughawiy berperan besar untuk memudahkan kaum muslimin untuk mendalami kandungan Al-Qur'an. menggali informasi keagamaan dalam kitab gundul. dan berkomunikasi dengan para penutur berbahasa Arab. Mu'jam lughawiy dianggap sebagai senjata utama yng harus dimiliki untuk mendapatkan pemahaman yang benar atas kata-kata. frase. kalimat. bahkan pola kalimat yang sukar dimengerti. karena di setiap disiplin ilmu tertentu sering kali menggunakan istilah-istilah partikular.

\section{Klasifikasi $M$ Mu'jam}

Mu'jam dapat dikategorisasikan sesuai dengan aspek maupun sudut pandang tertentu. Dari segi kuantitas bahasa yang digunakan. Mu'jam dapat diklasifikasikan menjadi. pertama. Mu'jam Ekabahasa (monolingual) yang isinya hanya menampilkan satu bahasa contohnya Munjid fi al-Lughah. Kedua. adalah Mu'jam dwibahasa (bilingual) yang isinya disajikan dalam dua macam bahasa misalnya Kamus Munawwir ArabIndonesia. Sementara yang ketiga adalah mu'jam multibahasa (multi lingual) misalnya kamus Arab-Indonesia-Inggris. ${ }^{16}$

Sementara dari segi kata. Mu'jam dapat dibagi menjadi dua yaitu Mu'jam al Alfadz (Kamus Kata) dan Mu'jam al Ma'ani (Kamus Tematik). ${ }^{17}$ Mu'jam al Alfadz adalah

\footnotetext{
${ }^{14}$ Taufiqurrahman.. Leksikologi... 144

${ }^{15}$ Ahmad Mukhtar Umar. Al Bahts Al Lughawi Inda al Arb. (Kairo : ‘Alam al Kutub. 1978) 116-117.

${ }^{16}$ Moh. Matsna HS. Kajian Semantik Arab Klasik dan Kontemporer.(Jakarta: Prenada Media Grup. 2016). 217.

${ }^{17}$ Moh. Matsna HS. Kajian Semantik Arab Klasik dan Kontemporer. 217
} 
kamus yang isinya lebih banyak memprioritaskan unsur fonologis (bunyi). morfologis (derivasi kata). sintaksis (gramatikal). semantic (makna). dan konteks peristiwa. Sementara Mu'jam al Ma'ani adalah kamus yang isinya terbatas pada topik kajian tertentu seperti Kamus Tata bahasa. Kamus Hukum. Kamus Kesehatan . kamus pertanian dan lainnya.

Selain itu Mu'jam juga dapat digolongkan berdasarkan jumlah entri (kepala kata) menjadi kamus besar (thesaurus) yang isinya sejumlah lebih dari 200 ribu entri. kamus sedang yang isinya sejumlah tidak kurang dari 40 ribu entri. dan kamus kecil yang isinya sejumlah tak kurang dari 10 ribu entri. $^{18}$

Ya'qub membagi $M u^{\prime} j a m$ kedalam beberapa jenis. yaitu: ${ }^{19}$

1) Mu'jam Lughawiy

Yakni Kamus Bahasa yang membahas kosakata sebuah Bahasa secara spesifik dan dilengkapi dengan contoh penggunaan kata-kata tersebut. Mu'jam Lughawi biasanya memuat satu Bahasa saja. sehingga pemaknaan diberikan melalui penyebutan sinonim atau definisi kata tersebut.

2) Mu'jam Tarjamah

Dikenal pula dengan kamus mazdujah (campuran) atau kamus bilingual yang memuat dua bahasa untuk menentukan persamaan makna dari dua kosakata dalam Bahasa yang berbeda. Mu'jam Tarjamah memuat kata-kata dari bahasa asing yang masingmasing dijelaskan dengan mencari padanan makna yang relevan dengan bahasa bahasa pengguna $M u^{\prime} j a m$.

3) Mu'jam Maudhu'i

Dikenal pula dengan nama Mu'jam maknawi atau kamus tematik. disebabkan kosakata yang termuat di dalamnya ditulis berdasarkan tema sesuai dengan pembahasan tertentu yang memiliki makna serumpun. Sebagai contoh untuk tema al mihnah (profesi) dimasukan kata fallaah (petani). muwaddhaf (pegawai) dan seterusnya.

\section{4) Mu'jam Isytiqaqi}

Dikenal pula dengan nama kamus Etimologis atau kamus derivatif. yaitu sebuah $M u$ 'jam yang memuat pembahasan mengenai asal muasal sebuah kata. Alhasil kamus derivatif/etimologis lebih berfungsi sebagai sumber informasi asal usul lafadz atau kata dalam Bahasa tertentu. Dalam Bahasa Arab biasanya mu'jam ini memuat penjabaran kata-kata dasar menjadi berbagai kata turunan melalui pola tashrif.

\footnotetext{
${ }^{18}$ Henry Guntur Tarigan. Pengantar Semantik. (Bandung: Angkasa. 1995). 178

${ }^{19}$ Imel Ya'qub. Al Ma'ajim Al Lughawiy Al 'Arabiyah. (Beirut: Dar al Ilm al Malayin. 1981). 15-20
} 


\section{5) Mu'jam Tathawwuri}

Merupakan Mu'jam yang lebih menekankan pada pembahasan sejarah perkembangan makna dari sebuah kata. Mu'jam ini juga dikenal sebagai Kamus evolutif yang menyediakan informasi terkait aspek semantik seperti perluasan dan penyempitan makna. pergeseran dan perubahan makna. faktor penyebab perubahan makna dan lainnya.

\section{6) Mu’jam Takhashshushiy}

Merupakan Mu'jam yang hanya memuat kosakata yang terdapat dalam satu bidang/disiplin ilmu secara khusus. Sebagai misal kamus hukum. kamus geografi. kamus fiqih dan sebagainya. Diantara contohnya adalah Mu'jam At-Tadzkirah yang disusun oleh Dawud Al-Anthaqi Al-Dharir. Kamus ini hanya menghimpun kata-kata khusus yang berkaitan dengan nama-nama tumbuhan dan serangga.

7) Mu'jam Dairah/Ma'lamah

Merupakan kamus yang berisi informasi tentang segala hal termasuk sejarah penggunaan Bahasa serta tokoh-tokoh yang terlibat dan lain sebagainya. Mu'jam ini lebih popular dikenal dengan istilah ensiklopedia (mawsu'ah) yang tidak hanya memberikan penjelasan sebuah kata dari aspek makna dan susunan derivasinya. tetapi juga memuat segala informasi yang tidak terkait makna leksikon (non linguistik).

8) Mu’jam Shuwary

Dikenal dengan kamus yang memuat penjelasan makna kata dengan lebih menonjolkan penggunaan visualisasi dari kata yang dimaksud menggunakan gambar dengan penjelasan definisi yang minim. Visualisai makna kata dianggap lebih efektif untuk menjelaskan definisi atau makna sebuah kata. Dengan simbol dan gambar dalam sebuah $M u$ 'jam merupakan terobosan baru dalam leksikologi.

Di samping Mu'jam- Mu'jam tersebut. Taufiqurrochman memberi tambahan beberapa tipe $M u$ 'jam lagi. ${ }^{20}$

\section{9) Mu'jam al-Kitab (Kamus Buku)}

Merupakan kamus yang berfungsi khusus untuk menjelaskan makna kata-kata yang terdapat dalam sebuah buku. Lazimnya. buku yang dilengkapi dengan mu'jam alkitab biasanya berupa buku pelajaran. sebab memang mu'jam jenis ini dianggap sebagai buku penunjang (kitab musa'id) bagi siswa. dan guru. untuk memperoleh pemahaman yang benar terhadap kosa kata yang terdapat dalam buku ajar yang digunakan.

${ }^{20}$ Taufiqurrahman.. Leksikologi...126-128 


\section{0) Mu'jam Digital}

Merupakan kamus yang berbentuk piranti lunak komputer (software) berupa program penerjemahan atau kamus bahasa yang berjalan melalui piranti elektronik seperti komputer. ponsel pintar. PDA. maupun perangkat elektronik yang lain. Software mu'jam digital dianggap memiliki kelebihan dari segi kepraktisan maupun kemudahan penggunaan. Kebanyakan mu’jam digital menggunakan sistematika berdasarkan urutan pengucapan (al-nutqi). Mu'jam digital memiliki kelebihan lainnya yaitu jumlah entri atau kata yang mencapai jumlah sangat banyak hingga tak terbatas. Diantara contoh kamus digital yang cukup popular adalah Kamus Al-Ma'aniy dan Kamus al-Mutarjim. ${ }^{21}$

11) $M u$ ’jam On-Line

Adalah mu'jam yang hanya bisa diakses jika terhubung dengan jaringan internet. Biasanya para penggunanya sering memanfaatkan jasa terjemahan mu'jam on-line pada saat menjelajahi (browsing) laman-laman atau website di internet. Diantara mu'jam on-line yang populer adalah Google Translate yang lamannya dapat melakukan proses penerjemahan puluhan bahasa asing di seluruh dunia. termasuk bahasa Arab.

\section{Sistematika Penulisan Mu'jam Lughawiy}

Semenjak Nasr bin Ashim memperkenalkan penyusunan huruf. para pakar penyusunan kamus semakin giat berinovasi untuk mengembangkan sistematika dalam menyusun Mu'jam Lughawiy 'Arabiy. Sampai saat ini. terdapat 5 (lima) model sistematika penyusunan Ma'ajim Arabiy. yaitu: ${ }^{22}$

1) Sistem Shautiy (Fonetik)

Model ini juga dikenal dengan istilah"Tartib al-Shawty wa al-Taqlibat" yang merupakan system penyusunan mu'jam perdana yang dipelopori oleh Khalil bin Ahmad al-Farahidi (791) dengan karya monumentalnya Mu'jam al Ain. Al Farahidi menyusun urutan kata-kata dalam mu'jamnya berdasarkan urutan huruf yang muncul mulai dari yang paling jauh secara makharijul huruf (out-put) bunyi bahasa dalam rongga tubuh manusia yang berperan dalam mengeluarkan bunyi. Karena itulah. sistem ini diberi nama "Tartib Shawty" atau sistem bunyi yang memiliki urutan sebagai berikut:

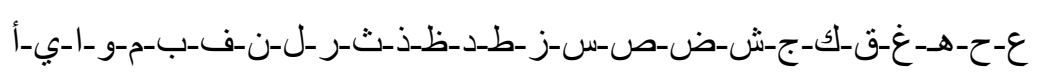

\footnotetext{
${ }^{21}$ Hastang. 'Efektifitas Kamus Bahasa Arab Berbasis Aplikasi Android Dalam Menerjemahkan Qiraah'. Didaktika : Jurnal Kependidikan. 11.1 (2019). 112-20<https://doi.org/10.30863/DIDAKTIKA.V11I1.158>.

${ }^{22}$ Taufiqurrochman. Pengembangan Kamus....13-17.
} 
Sistematika ini juga menggunakan pola "Taqlibaat" yaitu memberikan perhatian khusus pada segi derivasi huruf pada kata dasar yang kemudian disusun secara bolakbalik dengan menetapkan kata yang mempunyai makna (istikhdam) dan menghilangkan kata yang tidak memiliki makna (muhmal). Contohnya kata لعب yang setelah ditelaah dari ketiga huruf asalnya huruf yang paling jauh dari makharijul huruf adalah huruf $\varepsilon$ sehingga kata لعب ditempatkan di bagian lalu dibolak balik urutan hurufnya menjadi kemudian kata yang mempunyai makna dicantumkan penjelasannya sedangkan kata yang tidak memiliki makna diberi keterangan diabaikan.

2) Sistem Hija 'iy (Abjad)

Istilah lain dari pola ini adalah Tartib Alfaba'y al-Khash atau model pengurutan susunan huruf-huruf hijaiyah sesuai yang digagas oleh Nashr ibn 'Ashim yang diawali dengan Alif dan diakhiri dengan Ya ${ }^{e e}$ tanpa disertai pengulangan. serta tidak berpatokan pada makharijul huruf lagi. Diantara mu'jam yang menggunakan sistem ini adalah mu'jam berjudul Jamharatul Lughah yang disusun oleh Abu Bakar ibn Duraid (w.933). Mu'jam yang mengikuti pol aini tetap mengaplikasikan pola taqlibat atau pembolakbalikan urutan huruf dalam suatu kata.

3) Sistem Qafiyah (Sajak)

Pola ini juga disebut dengan istilah "Nidzam Qafiyah". yakni mu'jam yang mekanisme penyusunan kepala kata (entry) dan lemanya berpatoka pada huruf akhir dari suatu kata sehingga mu'jam ini sangat sesuai untuk para pujangga dan sastrawan yang berkeinginan untuk mengarang atau menggubah syair. Maka pada bagian abjad akan diisi dengan semua kosakata yang diakhiri dengan huruf أ . Diantara mu'jam yang menggunakan sistem ini yang sangat dikenal adalah Lisanul 'Arab yang ditulis oleh Ibnu Mandzur (w.1311). Mu'jam ini tersusun atas Bab (penentu huruf akhir) dan Fashal (penentu huruf awal). Contohnya pada bab 'Ain ditemukan kata-kata برع - جمع -صرع مدرسة Maka ketika mencari kata mu'jam qafiyah dapat dicari di

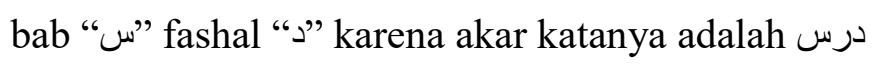

4) Sistem Alfaba'iy (Alfabetis)

Nama lain dari sistem ini adalah "Nidzam Alfabai al-'Aam". yaitu mu'jam yang susunan kosakatanya diurutkan berdasarkan huruf hija'iyah Arab secara alfabetis (abjad) yang dimulai dari huruf Alif hingga Ya'. Jika dibandingkan dengan model pendahulunya. model kedua ini sangat lekat dengan penggunaan akar kata atau kata dasar. Hal ini berimplikasi pada tuntutan bagi para pengguna kamus untuk memiliki pemahaman yang baik terkait gramatika bahasa Arab khususnya morfologi kata (ilmu 
sharf) karena sangat membantu dalam memudahkan penggunaan mu'jam. Hampir seluruh mu'jam yang diterbitkan pada abad 21 hingga sekarang lebih banyak mengadopsi sistem ini misalnya pada Munjid fil Lughah. Mu'jam al-Wasith. Kamus Al-Munawwir. dan sebagainya. Maka dari itu. jika ingin mencari arti suatu mufradat dalam kamus Arab-Indonesia dengan sistem ini. maka langkah yang dilakukan adalah mencari pada huruf pertama kata dasar atau bentuk aslinya (mujarrod)-nya dengan membuang huruf-huruf tambahannya. ${ }^{23}$ Sebagai contoh jika mencari arti kata maka dapat ditemukan pada bagian huruf قarena kata dasarnya adalah قبل

5) Sistem Nuthqiy (Artikulasi)

System ini dikenal dengan nama "Nidzam an-Nuthqie dengan karakteristik sistem pengurutan kosakatanya terletak pada urutan huruf pertama yang terucap. bukan melihat dari akar kata atau kata dasarnya. Karena itulah sistem ini dianggap cara yang paling mudah diantara sistem lainnya. Diantara Mu'jam yang menerapkan sistem ini antara lain Al Marja' yang ditulis oleh Syekh Abdullah Al Uyaili (w.1914) dan Kamus Ar Raaid yang disusun oleh Jibran Mas'ud (w.1930). Lebih lanjut berbagai keluaran terkini dari kamus digital berbasis android pada ponsel pintar . maupun kamus offline dan online juga banyak menerapkan sistem artikulasi karena diangggap lebih mengutamakan aspek kepraktisan ketika menggunakannya.

\section{METODE PENELITIAN}

Model Penelitian yang digunakan untuk mengeksplorasi pengalaman individu kemudian melakukan identifikasi mendalam terhadap pandangan. gagasan. dan kerangka berpikir sejatinya sangat besar peluangnya untuk diimplementasikan secara kualitatif. Karena pada dasarnya menampilkan fenomena nyata juga merupakan bentuk dari subjek penelitian kualitatif. Pada penelitian kualitatif seorang peneliti dapat menggagas suatu visualisasi dan deskripsi kompleks. menelaah kumpulan kata. laporan rinci dari sumber informan dan mengadakan kajian ilmiah pada kondisi yang natural. ${ }^{24}$ Metode kualitatif secara teknis dapat diimplementasikan untuk mengungkap secara detail aktifitas tertentu. ruang lingkup dan jalannya sebuah fenomena yang terjadi (dan sebagai cara yang dapat diimplementasikan untuk mendeskripsikan dan mengidentifikasi pengalaman individu yang diwujudkan dalam aktivitas kesehariannya). ${ }^{25}$ Maka dalam penelitian ini yang

\footnotetext{
${ }^{23}$ Agung Setiyawan. 'Problematika Penggunaan Kamus Arab-Indonesia Dalam Pembelajaran Tarjamah Di Pusat Pengembangan Bahasa UIN Sunan Kalijaga Yogyakarta'. Arabia. 8.1 (2017) $<$ https://doi.org/10.21043/ARABIA.V8I1.1934>.

${ }^{24}$ Muhammad Rijal Fadli. 'Memahami Desain Metode Penelitian Kualitatif'. Humanika. Kajian Ilmiah Mata Kuliah Umum. 21.1 (2021). 33-54 <https://doi.org/10.21831/HUM.V21I1.38075>.

${ }^{25}$ Cresswell. J. W.. Research Design: Qualitative. Quantitative and Mixed Methods Approaches. SAGE Publications. 2014. 33.
} 
bertujuan untuk mengidentifikasi problematika ketika menggunakan Mu'jam Lughawiy pada mahasiswa di Kota Bima. menggunakan metode kualitatif melalui pendekatan studi kasus dan mengaplikasikan semi-structured interview sebagai teknik pengumpulan data dan metode thematic analysis dalam rangka menganalisis data dan informasi yang terkumpul.

Metode Studi kasus dapat dipakai sebagai sebuah pendekatan dalam penelitian jika pertanyaan yang dicari jawabannya membutuhkan deskripsi yang luas dan mendalam melalui investigasi lengkap dan detail berdasarkan beberapa fenomena sosial yang sedang terjadi. Karena itu. Studi kasus memungkinkan peneliti untuk fokus secara mendalam pada kasus tertentu dengan mempertahankan perspektif holistik dan berbasis dunia nyata seperti dalam mempelajari siklus hidup individu dan perilaku kelompok kecil. ${ }^{26}$ Penelitian yang dilaksanakan pada bulan September 2019 sampai November 2021 ini memiliki tujuan memahami problematika yang dihadapi mahasiswa di Kota Bima ketika menggunakan Mu'jam Lughawiy dalam pembelajaran Bahasa Arab.

Dalam menentukan partisipan dari kalangan mahasiswa subjek. peneliti membuat kriteria sampling yang sesuai dengan tujuan penelitian. Cara ini dikenal dengan teknik purposive sampling. Teknik ini diaplikasikan melalui perekrutan partisipan dalam sebuah penelitian yang memprioritaskan individu dengan syarat memenuhi kriteria yang ditentukan. ${ }^{27}$ Dalam penelitian ini kriteria yang ditetapkan agar relevan dengan tujuan penelitian adalah para mahasiswa yang terdaftar pada Perguruan Tinggi Keagamaan di Kota Bima yang sedang menempuh atau pernah mengikuti Mata Kuliah Bahasa Arab sejumlah dua puluh orang.

Dalam penelitian ini populasinya tidak terbatas pada mahasiswa di satu Prodi. tetapi seluruh mahasiswa berstatus masih aktif terregistrasi sebagai mahasiswa di semester I sampai V pada berbagai Program Studi yang ada mata kuliah Bahasa arabnya. Pemilihan semester ini dilakukan dengan mempertimbangkan level kognitif dan pengalaman mahasiswa yang pernah berinteraksi dengan Mu'jam Lughawiy ketika mengikuti perkuliahan Bahasa Arab. Untuk mendapatkan partisipan dilakukan dengan mekanisme penyebaran selebaran memuat rangkuman gambaran penelitian serta sasaran penelitian. Selebaran ini dibagikan via grup WA mahasiswa yang selanjutnya mereka merekrut beberapa teman mahasiswanya untuk dijadikan informan. Informan inilah yang selanjutnya diinterview dengan teknik wawancara semi-terstruktur. dimana pewawancara

\footnotetext{
${ }^{26}$ Robert K. Yin. Case Study Research and Applications: Design and Methods. SAGE. 6th edn (Los Angeles: SAGE. 2018) <https://doi.org/10.1177/109634809702100108>.. 33-35.

${ }^{27}$ Sugiyono. Metode Penelitian Kuantitatif. Kualitatif dan R\&D. (Bandung: PT Alfabet. 2016).85.
} 
berkesempatan untuk berdialog secara langsung dengan informan tanpa harus terikat dengan draft pedowan interview. Wawancara semi terstruktur umumnya dipakai dalam penelitian kualitatif sebagai teknik andalan untuk menghimpun data. Wawancara dilaksanakan di lokasi yang telah disetujui Bersama antara peneliti dengan subjek. Demikian halnya waktu wawancara disesuaikan dengan waktu masing-masing responden.

Data dan informasi yang sudah dikumpulkan selanjutnya dianalisis secara tematik. untuk mengidentifikasi dan menganalisa pola atau tema yang dianggap penting untuk mendeskripsikan fenomena yang diteliti. Seperti teknik analisis data lainnya. metode thematic analysis. dilakukan melalui beberapa fase. memahami data. menyusun kode. dan menentukan tema. ${ }^{28}$ Tahap awal adalah memahami dan mengenali data lebih dekat. Tahap ini merupakan fase penting karena jika peneliti menjadi lebih akrab dengan data dan informasi yang diperolehnya maka semakin memberikan kemudahan bagi peneliti untuk melanjutkan tahap berikutnya. seperti menyusun interpretasi data yang terkumpul. Tahap mengenal secara dekat data yang diperoleh ini ditempuh melalui proses mendengarkan berulang kali rekaman interview yang sudah terlaksana.

Ketika mendengarkan kembali rekaman interview setidaknya dilaksanakan sebanyak minimal dua kali. Selanjutnya. perlu disusun transkrip wawancara pada tiap rekaman wawancara agar peneliti memperoleh bayangan dan memahami sedikit demi sedikit terkait perilaku obyek penelitian. Dikatakan pula sejatinya proses analisa data sebenarnya sudah berjalan sejak proses menyimak rekaman dan mendeskripsikannya kedalam transkrip wawancara. Tahapan berikutnya dalam analisis tematik adalah menyusun kode. Kode merupakan symbol atau ilustrasi dari pecahan data yang bersumber dari transkrip yang sesuai dengan topik penelitian. dan diasumsikan dapat memberikan jawaban atas apa yang ditanyakan dalam penelitian. Apabila seluruh data sudah ditetapkan masing-masing kodenya. kode tersebut diklasifikasikan berdasarkan keidentikan makna masing-masing. Dapat dikatakan bahwa kode yang maknanya identik akan dikelompokkan dalam satu grup yang sama. Grup inilah yang selanjutnya akan menggambarkan pola tertentu dari fenomena yang sedang diteliti.

\footnotetext{
${ }^{28}$ Heriyanto. 'Thematic Analysis Sebagai Metode Menganalisa Data Untuk Penelitian Kualitatif'. Anuva: Jurnal Kajian Budaya. Perpustakaan. Dan Informasi. $2.3 \quad$ (2018). $317-24$ $<$ https://doi.org/10.14710/ANUVA.2.3.317-324>.
} 


\section{HASIL DAN PEMBAHASAN}

Dari hasil penelitian yang telah ditempuh. ditemukan bahwa sebgian besar informan yang diwawancarai menyatakan bahwa mereka memiliki Mu’jam Lughawiy dengan model bilingual/dwibahasa. baik Arab-Indonesia maupun Indonesia Arab. Sebagian besar informan yang diwawancarai juga menyatakan bahwa Mu'jam Lughawiy baru dimiliki saat mereka menempuh jenjang perkuliahan. Hal ini disebabkan karena baru pada jenjang perkuliahan mereka bertemu dengan mata kuliah Bahasa Arab. Sebelumnya tidak dimiliki olh mereka karena mata pelajaran Bahasa Arab tidak diajarkan di bangku sekolahnya karena statusnya sekolah umum atau sekolah kejuruan umum. Hanya 50 persen dari total subjek yang pernah mempunyai Mu'jam Lughawiy sejak masih duduk di SMA/MA maupun SMP/MTs karena ada mata pelajaran Bahasa Arab yang dipelajarinya. Apalagi bagi yang menempuh Pendidikan di pondok pesantren maka rata-rata mereka sudah memiliki Mu'jam Lughawiy.

Dari paparan tersebut ada beberapa problematika yang ditemukan dalam hal motivasi untuk memiliki Mu'jam Lughawiy. Kendala yang paling mendasar adalah karena para mahasiswa belum memiliki motivasi yang cukup positif untuk mempelajari Bahasa Arab sehingga merasa belum terlalu membutuhkan untuk memiliki Mu'jam Lughawiy. Dari problemtika ini tentu saja dapat dicari faktor penyebabnya dari beberapa aspek. Dari aspek internal dapat dilihat pada rendahnya minat mahasiswa itu sendiri untuk mempelajari Bahasa arab serta dari aspek eksternal seperti mutu pendidik yang mengajari mereka Bahasa Arab. model dan pengalaman belajar Bahasa Arab yang pernah dialami hingga lingkungan pembelajaran Bahasa Arab yang kurang mendukung. Problem selanjutnya adalah aspek ekonomi karena hampir sebagian besar mahasiswa berasal dari kalangan yang kurang mampu sehingga untuk memiliki Mu'jam Lughawiy versi cetak yang ideal membutuhkan dana yang tidak murah.

Selanjutnya bentuk Mu'jam Lughawiy yang dimiliki oleh mayoritas para informan yakni model digital atau berbasis aplikasi yang diunduh dan dipasang di handphone mereka yang berbasis android. Alasan menjatuhkan pilihannya pada bentuk non-cetak ini adalah karena aspek efektifitas dan efesiensi. Menurut mereka penggunaannya sangat gampang. tidak memerlukan ekstra biaya untuk memilikinya. sangat efisien terkait waktu yang dibutuhkan untuk mendownload dan menginstallnya. tampilan dan modelnya sangat menarik. serta tidak ada kesulitan untuk dibawa ke manapun (portable). Mereka juga biasanya mengakses Mu'jam Lughawiy Arabiy secara online seperti melalui laman google translate jika menginginkan terjemahan frasa dan 
kalimat dalam jumlah banyak atau paragraf. Hanya 20 persen dari informan saja yang menyatakan bahwa mereka juga memiliki Mu'jam Lughawiy dalam bentuk cetak karena masih memperhitungkan aspek kelengkapan isi. nyaman dibaca. serta motivasi untuk melatih kemampuan kebahasaannya khususnya aspek gramatikal.

Namun demikian terdapat kendala bagi sebagian kecil mahasiswa yang bahkan untuk memiliki dan menggunakan Mu'jam Lughawiy versi digital maupun online tidak semuanya dapat terwujud karena memiliki keterbatasan dalam memiliki ponsel pintar berbasis android yang harganya juga relatif tidak murah. Jikalau pun ada yang memilikinya. sebagian kecil dari mereka hanya mampu membeli ponsel pintar dengan spesifikasi jadul yang kurang kompatibel dengan perkembangan aplikasi Mu’jam Lughawiy yang terbaru. Di samping itu kendala juga muncul karena tidak semua wilayah asal mahasiswa terjangkau oleh sinyal internet atau terjangkau sinyal internet namun tidak mampu membeli paket internet sehingga terkendala ketika menggunakan $M u$ 'jam Lughawiy versi online. Mereka hanya dapat menggunakannya ketika berada di tempattempat yang menyediakan akses internet gratis seperti di kampus.

Ketika penulis menerapkan penggunaan Mu'jam Lughawiy dengan sistematika fonetik maupun sistem sajak. 90 persen mahasiswa mengalami kesulitan untuk menggunakannya karena tidak familiar bahkan dianggap lebih tidak praktis. Karena itulah dari aspek sistematika penyusunannya. seluruh mahasiswa lebih banyak yang memilih untuk menggunakan Mu’jam Lughawiy sistematikanya berbasis Nutqiyyah (Artikulasi). Argumentasi yang diajukan adalah lebih memberikan kemudahan dalam aspek kepraktisan dan kemudahan ketika proses pencarian kata yang ingin dicari terjemahannya karena hanya mencocokkan huruf awalnya saja tanpa repot harus mengidentifikasi atau mencari akar katanya (fi'il madhiy) sebagaimana yang lazin dipakai dalam mu’jam Abjadiy. Problematika yang masih menghampiri mereka masih terkait rendahnya kompetensi dan penguasaan pengetahuan tashrif (morfologi kata bahasa Arab) dan kaidah Nahwu (sintaksis). Hal ini menjadi informasi berharga bagi para pendidik Bahasa Arab di segala jenjang lebih optimal dalam mentransformasikan pengetahuan dan kompetensinya dalam rangka meningkatkan kompetensi para peserta didik terkait kemampuan penguasaan tata Bahasa Arab.

Fakta di atas kemudian ditambah dengan temuan kendala pada mahasiswa ketika berinteraksi dengan Mu'jam Lughawiy. Problematika di atas berimplikasi pada kemampuan penggunaan Mu'jam Lughawiy dengan sistem alfabetik. Dapat dilihat bahwa 70 persen informan menyatakan kesulitannya ketika menentukan bentuk dasar/akar suatu 
kata dalam Mu'jam Lughawiy. 10 persen menyatakan kesulitannya ketika menentukan makna kata yang tepat dan 20 persen menyatakan kesulitannya ketika menentukan akar suatu kata sekaligus menentukan makna kata yang tepat. Sulitnya menentukan makna kata yang tepat sebagaimana yang dihadapi sebagian mahasiswa ditengarai disebabkan karena rendahnya frekuensi literasi Bahasa Arab yang mereka miliki sehingga berpengaruh terhadap pengalaman dan rasa Bahasa Arab yang tidak optimal. Hal ini terjadi ketika mereka menggunakan Mu'jam Lughawiy Indonesia-Arab maupun ArabIndonesia.

Hal tersebut justru berimplikasi pada frekuensi penggunaan Mu'jam Lughawiy yang menunjukkan data bahwa meskipun mahasiswa mempunyai Mu'jam Lughawiy. jika mereka menjumpai kesulitan untuk mengetahui makna dibalik kata atau kalimat dalam Bahasa Arab maupun terjemahannya. mereka lebih memilih dengan menanyakan langsung secara lisan kepada dosen pengampu mata kuliah atau kepada beberapa rekannya yang dianggap lebih mengetahui. Penggunaan Mu'jam Lughawiy secara faktual hanya dilakukan pada saat menyelesaikan tugas perkuliahan dari dosen pengampu mata kuliah Bahasa arab. baik tugas tertulis maupun lisan. Dari sini dapat dilihat bahwa sebagian besar mahasiswa tidak maksimal mengaplikasikan kegunaan dan kelebihan Mu’jam Lughawiy sebagai jalan keluar dari kebuntuan Bahasa dari segi makna (semantik). Tidak sedikit informasi dan pengetahuan kebahasaaraban mampu dikembangkan ketika sering berinteraksi dengan Mu'jam Lughawiy. Indikator hal ini dapat dilihat dari preferensi mereka terhadap Mu'jam Lughawiy yang lebih mengutamakan pada aspek kepraktisan maupun kemudahan dan masih belum optimalnya tingkatan frekuensi untuk menggunakan Mu’jam Lughawiy dalam aktifitasnya seharihari.

Sementara itu menurut hemat penulis untuk meminimalisir berbagai problematika dalam menggunakan Mu'jam Lughawiy sebagaimana paparan di atas. maka jalan keluarnya perlu kerja sama berbagai pihak. baik guru. pendidik. pembelajar. Lembaga Pendidikan. dan keluarga serta masyarakat. Di tangan pendidiklah tersimpan harapan terbesar untuk dapat menciptakan proses dan pengalaman belajar terbaik bagi para pembelajar Bahasa Arab melalui penggunaan metode. media. strategi. materi. sumber belajar. dan evaluasi pembelajaran Bahasa Arab. Hal ini diharapkan dapat meningkatkan motivasi dan prestasi belajar Bahasa Arab bagi para pembelajar Bahasa Arab sehingga mereka dapat memaksimalkan dirinya untuk mengembangkan kemampuan Bahasa 
arabnya yang salah satu indikatornya adalah memiliki keterampilan yang baik dalam menggunakan Mu'jam Lughawiy.

\section{PENUTUP}

Mu’jam Lughawiy memiliki kedudukan yang mustahil dapat dijauhkan dari proses Pendidikan bahasa. terutama bagi yang ingin mempelajari bahasa asing. termasuk bahasa Arab. Sejarah mencatat bahwa keberadaan mu'jam arabi mengalami transformasi baik dari wujud bentuk fisiknya maupun sistematika dan model penyusunannya. Melalui penelitian ini menunjukkan informasi pada kita bahwa kecenderungan mahasiswa terhadap Mu'jam Lughawiy adalah karena faktor efisiensi finansial. kepraktisan dan kemudahan penggunaannya. Mereka mengandalkan kecanggihan teknologi komunikasi dan informasi terkini dengan menggunakan Mu'jam Lughawiy berbentuk digital maupun online dan menggunakan sistematika berbasis artikulasi. Problematika yang muncul ketika menggunakan Mu'jam Lughawiy dengan sistem alfabetik adalah lemahnya pengetahuan gramatikal yang bersumber dari tidak maksimalnya pembelajaran Bahasa Arab yang telah mereka tempuh di jenjang sebelumnya karena berbagai faktor baik internal maupun eksternal. Apapun temuan penelitian ini tidak dimaksudkan untuk menggeneralisasi problematika mahasiswa secara menyeluruh mengingat terbatasnya fokus penelitian dan tingkatan mahasiswa yang menjadi subjek penelitian. Penelitian lanjutan di masa mendatang dapat dilakukan dengan menitikberatkan kepada subjek lain di tingkatan yang berbeda. 


\section{DAFTAR PUSTAKA}

Ahmad Mukhtar Umar. Al Bahts Al Lughawi Inda al Arb. Kairo : 'Alam al Kutub. 1978.

Ar-Razy. Muhammad bin Abu Bakar bin Abdul Qadir. Mukhtar al-Shihaah. Beirut: Maktabah Lubnan. 1995.

Athar. Ahmad Abdul Ghafur. Muqaddimah Al-Shihah. Beirut. Dar Al-Ilm Lil Malayin. 1979.

Cresswell. J. W.. Research Design: Qualitative. Quantitative and Mixed Methods Approaches. SAGE Publications. 2014.

Devianty. Rina. 'Bahasa Sebagai Cermin Kebudayaan'. JURNAL TARBIYAH. 24.2 (2017) $<$ https://doi.org/10.30829/TAR.V24I2.167>

Fadli. Muhammad Rijal. 'Memahami Desain Metode Penelitian Kualitatif'. Humanika. Kajian Ilmiah Mata Kuliah Umum. 21.1 (2021). 33-54 $<$ https://doi.org/10.21831/HUM.V21I1.38075>

Hastang. 'Efektifitas Kamus Bahasa Arab Berbasis Aplikasi Android Dalam Menerjemahkan Qiraah'. Didaktika : Jurnal Kependidikan. 11.1 (2019). 112-20 $<$ https://doi.org/10.30863/DIDAKTIKA.V11I1.158>

Heriyanto. 'Thematic Analysis Sebagai Metode Menganalisa Data Untuk Penelitian Kualitatif'. Anuva: Jurnal Kajian Budaya. Perpustakaan. Dan Informasi. 2.3 (2018). 317-24<https://doi.org/10.14710/ANUVA.2.3.317-324>

Iskandarwassid. dan Dadang Sunendar. Strategi Pembelajaran Bahasa. Bandung: Remaja Rosdakarya. 2011.

Izzan. Ahmad. Metodologi Pembelajaran Bahasa Arab. Bandung: Humaniora. 2009.

Maharani. Tisa. and Endang Setiyo Astuti. 'Pemerolehan Bahasa Kedua Dan Pengajaran Bahasa Dalam Pembelajaran BIPA'. Jurnal Bahasa Lingua Scientia. 10.1 (2018). 121$42<$ https://doi.org/10.21274/LS.V10I1.938>

Matsna. Moh. HS. Kajian Semantik Arab Klasik dan Kontemporer.Jakarta: Prenada Media Grup. 2016.

Mualif. A. 'Orisinalitas Dan Elastisitas Kosakata Dalam Bahasa Arab'. (LISANUNA): Jurnal Ilmu Bahasa Arab Dan Pembelajarannya. 9.1 (2020). 40-51 $<$ https://doi.org/10.22373/LS.V9I1.6731>

Setiyawan. Agung. 'Problematika Penggunaan Kamus Arab-Indonesia Dalam Pembelajaran Tarjamah Di Pusat Pengembangan Bahasa UIN Sunan Kalijaga Yogyakarta'. Arabia. 8.1 (2017) <https://doi.org/10.21043/ARABIA.V8I1.1934>

Shalihah. Siti. 'Terjemah Bahasa Arab Antara Teori Dan Praktik'. At-Ta'dib. 12.2 (2017). 183-202<https://doi.org/10.21111/AT-TADIB.V12I2.1144>

Sugiyono. Metode Penelitian Kuantitatif. Kualitatif dan R\&D. Bandung: PT Alfabet. 2016.

Suhaimi. Suhaimi. 'MU'JAM 'ARABÄ a DAN URGENSINYA DALAM PEMBELAJARAN BAHASA ARAB DI PERGURUAN TINGGI AGAMA ISLAM'. JURNAL ILMIAH DIDAKTIKA: Media Ilmiah Pendidikan Dan Pengajaran. 12.1 (2011). 134-48 $<$ https://doi.org/10.22373/JID.V12I1.443>

Tarigan. Henry Guntur. Pengantar Semantik. Bandung: Angkasa. 1995.

Taubah. Miftachul. and Ilzam Dhaifi. 'RESEPTIF DAN PRODUKTIF DALAM BAHASA 
ARAB'. Lahjah Arabiyah: Jurnal Bahasa Arab Dan Pendidikan Bahasa Arab. 1.1 (2020). 33-36<https://doi.org/10.35316/LAHJAH.V1I1.574>

Taufiqurrahman.. Leksikologi Bahasa Arab. Malang: UIN Malang Press. 2008.

Taufiqurrochman. Pengembangan Kamus Tarbiyah Arab-Indonesia. Indonesia-Arab. UIN Maliki Malang. 2015.

Ya'qub. Imel. Al Ma'ajim Al Lughawiy Al 'Arabiyah. Beirut: Dar al Ilm al Malayin. 1981.

Ghaly. Wajdy Rizqi dan Husain Nassar.. Al-Mu'jamaat Al-Arabiyyah Biblughrafiyah Syamilah Masyruhah. Kairo: al-Haie ah al-Mishriyah al-A“emmah. 1971.

Yin. Robert K.. Case Study Research and Applications: Design and Methods. SAGE. 6th edn (Los Angeles: SAGE. 2018) <https://doi.org/10.1177/109634809702100108> 